\title{
Carbamazepine and its Synthesis Related Impurities Profile Compilation and its Monograph Dispute for the Best Regulatory Practice: A Review
}

\author{
Samrat Debnath, Jeyaprakash Mari Raju*, Rupika Sunidhi Chennapragada
}

Department of Pharmaceutical Analysis, JSS College of Pharmacy, JSS Academy of Higher Education and Research, Ooty, Nilgiris, Tamil Nadu, INDIA.

\begin{abstract}
Carbamazepine (CBZ) is a widely-used anticonvulsant drug, with a high prescription rate. However, there seem to be certain inconsistencies regarding the number of reported impurities of the drug. A monograph study of the drug reveals the difference in the numbers of reported impurities of the drug, i.e., different monographs have reported dissimilar number of impurities for the same drug. Literature survey reveals that over 10 routes of synthesis are currently existing for the synthesis of $\mathrm{CBZ}$, as well as employing over 25 reactants across the synthetic routes. There also appears to be a lack of mention of the number of carcinogenic impurities of the drug. This review article aims to summarize the potential for the presence of potential carcinogenic impurities and its carcinogenicity in the drug of CBZ. Which can arise from the various reactants involved in the
\end{abstract}

manufacturing process of the drug and their individual role in imparting carcinogenicity to the final formulation.

Key words: Carbamazepine, Impurity related substances, Carcinogenic substances, Reactants, Synthesis.

Correspondence

Dr. MR Jeyaprakash

Assistant Professor, Department of Pharmaceutical Analysis, JSS College of Pharmacy, Ooty, Nilgiris-643001, Tamil Nadu, INDIA.

Phone: +919952335392

Email: jpvis7@jssuni.edu.in

DOI: 10.5530/jyp.2020.12.80

\section{INTRODUCTION}

Carbamazepine (CBZ), ${ }^{1}$ a known compound for anticonvulsant and analgesic activity, is used to control seizures and treat pain resulting from trigeminal neuralgia. The drug Carbamazepine is a first-generation anticonvulsant approved by United States by 1967 and UK in 1965, CBZ developed by J. R. Geigy (Novartis) in the 1950s and has been commercialized under the trade name of Tegretol ${ }^{\oplus 2}$ for the treatment of epilepsy, trigeminal neuralgia (in 1962) and mania. This anticonvulsant molecule was approved by the FDA in the year 1965. Since then, it has become the most normally prescribed first-line drug for epilepsy. Apart from that, Carbamazepine is also used to treat bipolar disorder. ${ }^{3}$ The chemical name of the drug is $5 \mathrm{H}$-dibenzo [b,f]azepine-5-carboxamide. The molecular formula is $\mathrm{C}_{15} \mathrm{H}_{12} \mathrm{~N}_{2} \mathrm{O}$. The physical description of the drug is a white to yellowish-white, crystalline powder; ${ }^{4-7}$ odourless practically insoluble in water and ether but soluble in ethanol. ${ }^{8}$ The molecular weight of the drug is $236.27 \mathrm{~g} / \mathrm{mol}$. There are various methods such as LC-MS/MS, ${ }^{9,10}$ HPLC, ${ }^{11-20}$ HPTLC, ${ }^{21}$ UV-Visible spectroscopy ${ }^{22-27}$ micellar electro kinetic chromatography and UFLC ${ }^{28}$ available for the profiling quantitative analysis of carbamazepine.

\section{Mechanism of Action and Clinical Uses}

CBZ is a sodium channel blocker and it is mainly work by binds deferentially to energies gated sodium channel in there inactive conformation..$^{29}$ It has also consequence on the serotonin system but also the relevance to its anti-seizure effect is tentative. CBZ is moderately slowly but well engaged in oral running. In the drug structure, the double bond between C-10 and C-11 is the most reactive site chemically, pharmacologically and metabolically. ${ }^{2}$ The mechanism of action of CBZ has not yet been fully revealed and is widely discussed. One of the major hypotheses is that the drug carbamazepine impedes sodium channel firing, treating seizure bustle. ${ }^{30}$ Animal research studies have established that carbamazepine wields its effects by lowering polysynaptic nerve response and inhibiting post-tetanic potentiation. In both cats and rats, carbamazepine has shown that decrease in pain is caused by infraorbital nerve stimulation. ${ }^{3}$ Decrease in the action potential in the nucleus ventral's of the thalamus into the brain and reticence of the lingual mandibular reflex was observed in other studies after carbamazepine use. Carbamazepine works by binding to voltage-dependent sodium channels and preventing action potentials that generally leads to stimulatory effects on the nerves. ${ }^{31}$ In bipolar disorder, carbamazepine is also used to increase dopamine turnover which leads to increase GABA transmission, treating manic and depressive symptoms. ${ }^{4}$ It's delivered that, CBZ used for many purposes from last five decades.

\section{Bioavailability and Pharmacokinetics}

The range of the bioavailability of CBZ is $75-85 \%$ of an ingested dose. The plasma protein binding affinity to CBZ is $75 \%-80 \%{ }^{32-35}$ The maximum portion of Carbamazepine is largely metabolized in the liver. CYP3A4 hepatic enzyme is one of the primary enzymes which metabolizes CBZ into its active metabolite, carbamazepine-10, 11 -epoxide, ${ }^{36}$ which is further metabolized to its trans-diol form by the enzyme epoxide hydrolase. But the major problem about this drug is the resistance to the drugs rise by $30 \%$ in an epileptic patient.

\section{Side Effect of Carbamazepine}

Nowadays one major problem is the rise in resistance to drugs by $30 \%$ in epileptic patients, which may be attributed to the altered metabolism in the patients with modified genotypes. Though it is very effective, the drug suffers from undesirable side effects. There are several side effects 
reported in the patients and the commonly reported ones include ataxia, dizziness, drowsiness, nausea and vomiting. More common side effects include blurred vision or double vision, continuous back-and-forth eye movements. Meanwhile less common effects are actions that are out of control, behavioural changes, confusion, agitation, or hostility, diarrhoea, discouragement, drooling, fear, feeling of unreality, feeling sad or empty, headache, increase in seizures, irritability, lack of appetite, loss of balance control, loss of interest or pleasure, muscle trembling, jerking, or stiffness, nausea, other problems with muscle control or coordination, sense of detachment from self or body, shakiness and unsteady walk, shuffling walk, stiffness of the arm or leg, sudden, wide mood swings, talking, feeling and acting with excitement, thoughts or attempts of killing oneself, tiredness, trouble concentrating, trouble sleeping, twisting movements of the body, uncontrolled movements, especially of the face, neck and back, unusual drowsiness vomiting. Other side effects include pruritus, speech disturbance, amblyopia and xerostomia.

This drug also exhibits serious and sometimes fatal dermatologic reactions, especially with the hereditary allelic variant HLA-B ${ }^{\star} 1502$. Hence, at-risk patients are to be separated prior to prescribing CBZ. The treatment should not be started in patients that tested positive unless the benefits outweigh the risks. If there is any type of dermatologic effect then the drug must be discontinued. Research has also reported aplastic anaemia and agranulocytosis. Pre-treatment haematological trying has to be obtained and $\mathrm{CBC}$ must be sporadically screened. Drug termination should be considered if substantial bone marrow depression evolutions are observed.

\section{LIST OF IMPURITIES PRESENTED AS PER STANDARD MONOGRAPH BOOKS}

In the $\mathrm{CBZ}$ the current problem is the reported number of impurities ${ }^{37}$ in the official monographs for the drug CBZ. To illustrate, the Indian Pharmacopoeia mentions only two impurities, while the British pharmacopoeia mentions a total of seven impurities and the Japanese and the United State Pharmacopoeia mention five and two impurities respectively [Table 1].

This implies that, there exists a lack of uniformity with respect to the officially reported impurities. That may be chalked up to the fact that, there appear to be several routes of synthesis available for CBZ (Figure 1). Among the several routes of synthesis, there seem to be several reactants.

Table 1: List of Pharmacopoeia impurities Carbamazepine.

\begin{tabular}{|c|c|c|c|c|c|}
\hline \multirow{2}{*}{$\begin{array}{l}\text { S. } \\
\text { No }\end{array}$} & \multirow{2}{*}{$\begin{array}{c}\text { Name of Impurity } \\
\text { EP }\end{array}$} & \multicolumn{3}{|c|}{ Pharmacopeia Code } & \multirow{2}{*}{ Structure } \\
\hline & & BP & US & & \\
\hline 1 & 10,11 dihydrocarbamazepine & Impurity A & Impurity A & Related Compound A & \\
\hline 2 & 9-methylacridine & Impurity B & Impurity B & - & \\
\hline 3 & N-Carbamoylcarbamazepine & Impurity C & Impurity C & - & \\
\hline 4 & Iminostilbene & Impurity D & Impurity D & Iminostilbene & \\
\hline 5 & Iminodibenzyl & Impurity E & Impurity E & - & \\
\hline 6 & 5-Chlorocarbonyliminostilbene & Impurity F & Impurity F & - & \\
\hline 7 & 10-Bromocarbamazepine & Impurity G & - & - & \\
\hline
\end{tabular}


It was also observed that a few of those reactants have the potency of carcinogenicity. However, there is also lack of a proper justification that, whether the mutagenic reactants are present in the final product as an impurity. Even though $\mathrm{CBZ}$ is a drug that came into the market over fifty years ago, there is no clear opinion on the possible presence of genotoxic impurities in the official monographs. The presence of any such manufacturing process-related impurities has not been reported in any official monographs as well.

\section{CARCINOGENIC RESULT OF PRESENT IMPURITIES IN THE MANUFACTURING PROCESS OF CARBAMAZEPINE}

This argument is also evidenced by the statement in the recent USFDA file for CBZ stating that the carcinogenic effect of the drug is yet unknown in humans. Hence, the confirmation that such reactants possess carcinogenicity will confirm the fact that the final marketed product will also possess carcinogenic substances. The list of reactant names are given in Table $2 .^{1}$

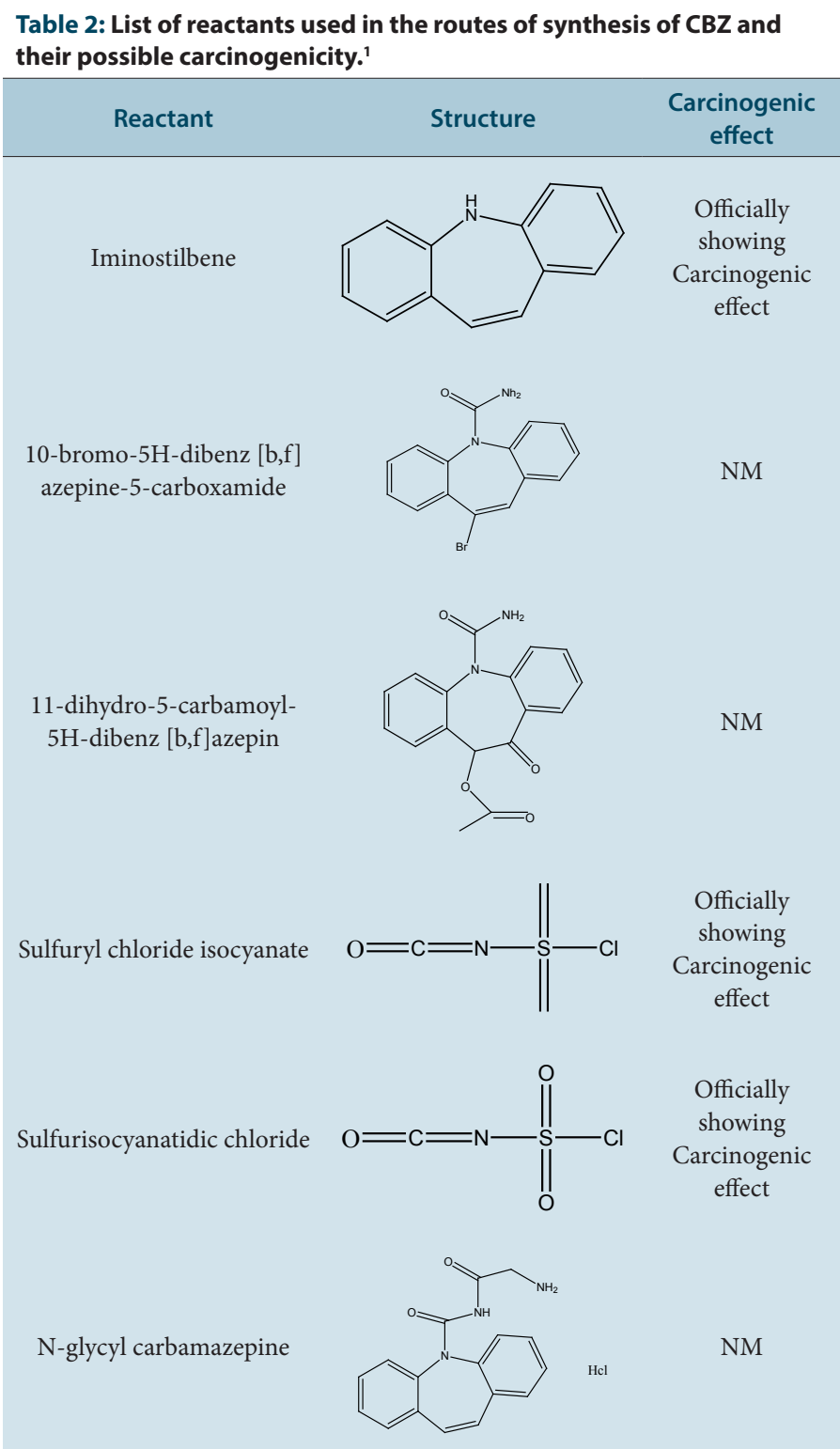

$\mathrm{N}$-acetyl carbamazepine<smiles>CC(=O)NC(=O)N1c2ccccc2C=Cc2ccccc21</smiles>

NM

5, 11-dihydro-10H-dibenzo $[\mathrm{b}, \mathrm{f}]$ azepin-10-one<smiles>CC(=O)NC(=O)N1c2ccccc2C=Cc2ccccc21</smiles>

NM

10-Methoxy Iminostilbene<smiles>c1ccc(Nc2ccccc2)cc1</smiles>

NM

2, 2'-ethylenediamine<smiles>Nc1ccccc1CCc1ccccc1N</smiles>

NM

2-Nitrotoluene<smiles>CC1CCCCC1[N+](=O)[O-]</smiles>

Officially showing Carcinogenic effect

2, 2'-Dinitrobibenzyl<smiles>O=[N+]([O-])c1ccccc1CCc1ccccc1[N+](=O)[O-]</smiles>

NM

2, 2'-Iminobisbenzaldehyde<smiles>O=CC1CCCCC1NC1CCCCC1C=O</smiles>

NM

Iminodibenzylcarbony<smiles>O=C(Cl)N1c2ccccc2CCc2ccccc21</smiles>

NM<smiles>CC(=O)NC(=O)N1c2ccccc2C=Cc2ccccc21</smiles>

NM

$\mathrm{N}$-acetyl carbamazepine<smiles>c1ccc2c(c1)CCc1ccccc1N2</smiles>

Officially showing Carcinogenic effect 


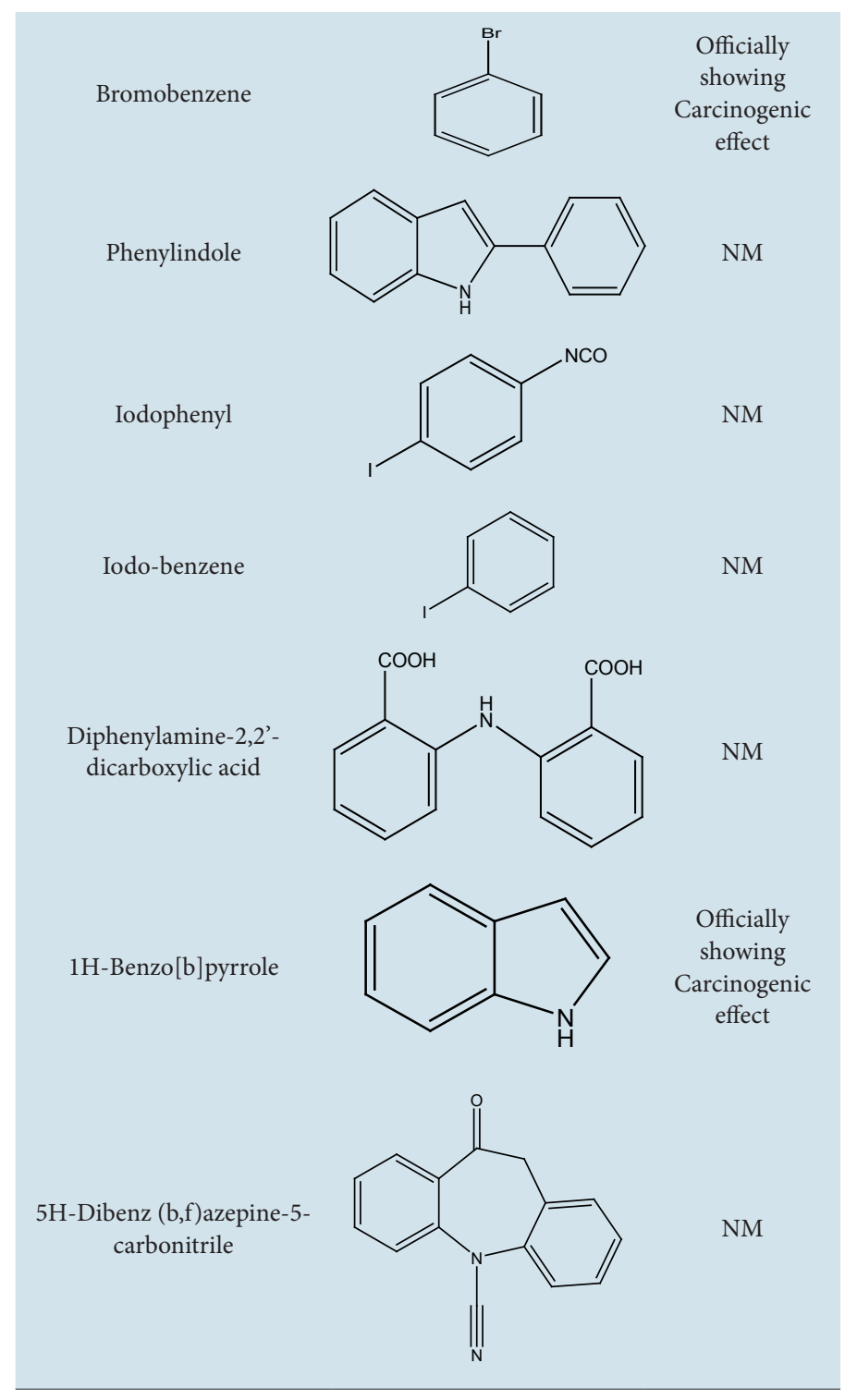

NM means Not mentioned

\section{CONCLUSION}

The drug CBZ is a quite old and yet highly prescribed anti-epileptic still in use. However, the existing analytical methods for the impurity profiling of the drug have seemingly reported the same compounds as those in the official monographs. Thorough monograph study on the drug, it was observed that the USP, the BP, the JP and the IP have reported different numbers of impurities for the same drug. Additionally, it was also identified that, were over 10 different routes of synthesis for the drug, all of which have a combined total of over 26 reactant molecules going into the process of synthesis. This raises a question about the actual number of impurities for the drug. Another revelation is the potential carcinogenicity of the reactants utilised. If a reactant is deemed to be a carcinogenic agent, using it for the synthesis of the drug might lead to the imparting of carcinogenic character to the final product. This becomes an issue especially when such carcinogenic reactants have not been identified for the drug. Hence, this review article highlighted the various monograph- listed impurities for the drug Carbamazepine and the several official and unofficial routes of synthesis for the same and the possible reactants that may have a role in imparting carcinogenic behaviour to the final product.

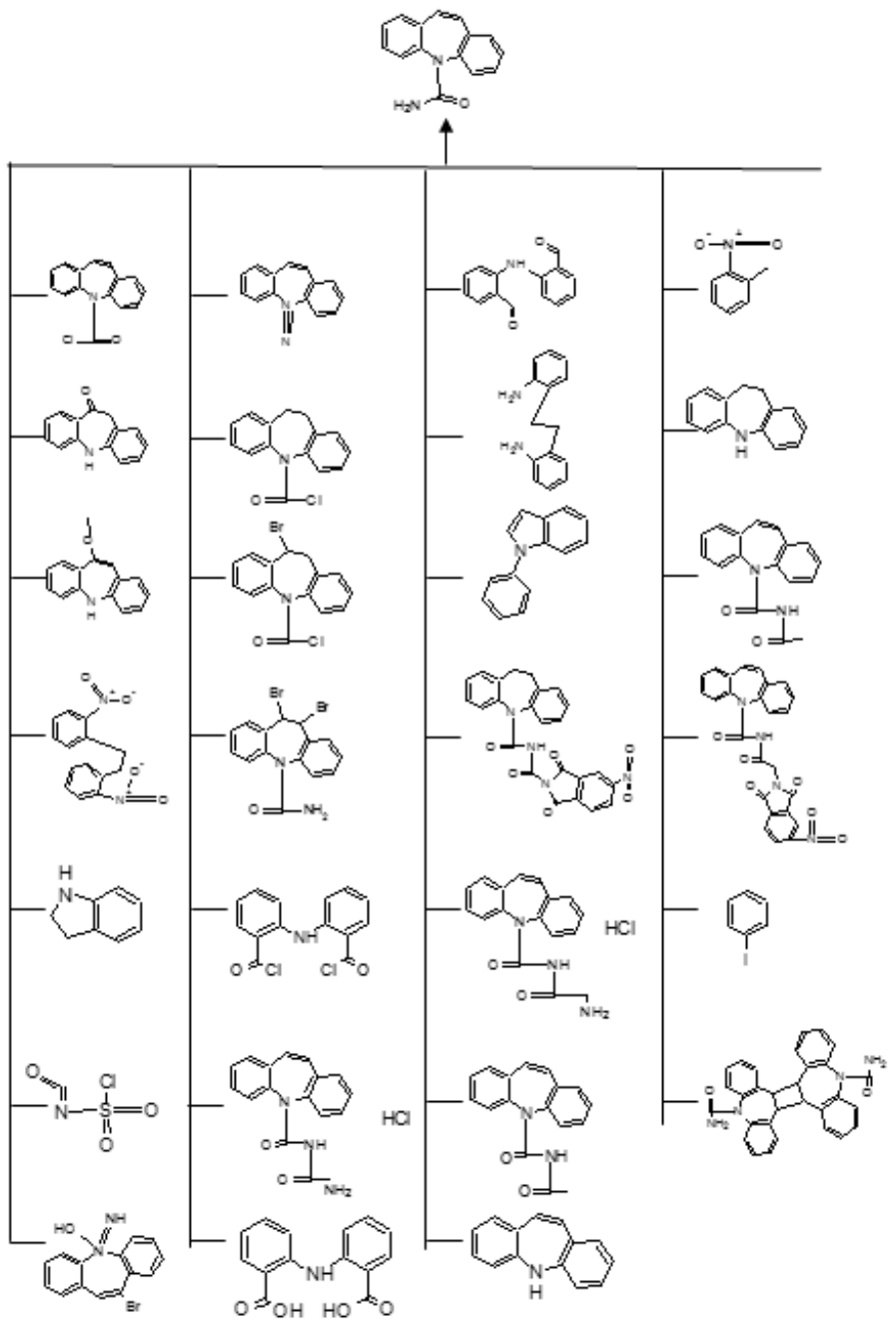

Figure 1: The several reactants utilised among the various existing routes of synthesis of the drug CBZ.

\section{ACKNOWLEDGEMENT}

The authors would like to concede, JSS College of Pharmacy for stretched this research work.

\section{CONFLICT OF INTEREST}

The authors declare no conflict of interest.

\section{ABBREVIATIONS}

CBZ: Carbamazepine; LC-MS/MS: Liquid chromatography mass spectroscopy; HPLC: High performance liquid chromatography; HPTLC: High performance thin layer chromatography; UFLC: Ultrafastliquid chromatography; FDA: Food and drug administration;USFDA: U S food and drug administration; USP: United States pharmacopoeia; BP: British pharmacopoeia; JP: Japanese pharmacopoeia; IP: Indian pharmacopoeia.

\section{REFERENCES}

1. http://www.molbase.com/en/synthesis298-46-4-moldata-27162.html

2. Tegretol®, Novartis, Drugs FDA. 2009

3. Heinz G, Sandra S, Benedikt A. Anticonvulsant drugs in bipolar disorder Dialogues Clin Neurosci. 1999;1(1):24-40.

4. Yasuo Y, Etsuo Y, Katsuhide T. Estimation of Initial Dissolution Rate of Drug 
Substance by Thermal Analysis: Application for Carbamazepine Hydrate. Pharm Development Tech. 2002;7(1):89-95.

5. Seefeldt K, Miller J, Alvarez-Nu NFEZ. Crystallization Pathways and Kinetics of Carbamazepine-Nicotinamide Cocrystals from the Amorphous State by in situ Thermo microscopy. Spectroscopy and Calorimetry Studies. J Pharm Sci. 2007;96(5):1147-58.

6. Buanz $A B$, Parkinson GN, Simon G. Characterization of CarbamazepineNicatinamide Cocrystal Polymorphs with Rapid Heating DSC and XRPD. Cryst Growth Des ACS Publication. 2011;11(4):1177-81.

7. Srinivasulu A, Pui SC, Reginald BHT. Structural Spectroscopic and Thermal Analysis of Cocrystals of Carbamazepine and Piracetam with Hydroquinone. J Chem Crystallogr. 2011;41(11):1604-11.

8. Joshi BV, Patil VB, Pokharkar VB. Compatibility Studies Between Carbamazepine and Tablet Excipients using Thermal and Non-thermal Methods. Drug Development and Ind Pharmacy. 2002;28(6):687-94

9. Xiu-Sheng M, Chris DM. Determination of Carbamazepine and Its Metabolites in Aqueous Samples Using Liquid Chromatography-Electrospray Tandem Mass Spectrometry. Anal Chem. 2003;75(15):3731-8.

10. EAbdel-Hamid AM, Oludotun AP. LC-MS/MS Determination of Carbamazepine, Pindolol and Theophylline in Human Serum. J Liquid Chroma Related Tech. 2003;26(12):1937-57.

11. David J, Peter GF, John OM. Phase I and Phase II Drug Metabolism: Terminology that we should Phase Out. Drug Metab Rev. 2005;37(4):575-80.

12. Stephen RC, Sperry DC, Michael H. Relative Bioavailability Estimation of Carbamazepine Crystal Forms using an Artificial Stomach-Duodenum Model. J Pharm Sci. 2006;95(1):116-25

13. Baldania SL, Bhatt KK, Mehta RS, et al. RP-HPLC estimation of venlafaxine hydrochloride in tablet dosage forms. Indian J Pharm Sci. 2008;70(1):124-8.

14. Eunkyung O, Eunmi B. Analysis of carbamazepine and its active metabolite, carbamazepine-10, 11-epoxide, in human plasma using high-performance liquid chromatography. Anal Bioanal Chem. 2006;386(6):1931-6.

15. Dzodic LJ. Determination of Carbamazepine and Its Impurities Iminostilbene and Iminodibenzyl in Solid Dosage Form by Column High-Performance Liquid Chromatography. J AOAC Int. 2010;93(4):1059-64.

16. Prasanna AD. Quantitative bioanalytical and analytical method development of dibenzazepine derivative, carbamazepine: A review. J Pharm Analysis 2015;5(4):213-22.

17. Zeynep A, YIImaz EM, Serap SA, Zeynep ET, et al. RP-HPLC method for the simultaneous determination of carbamazepine and nilotinib: Application solubility studies. The Pharm Chem J. 2016;3(4):1-10

18. Busra KI, Afife B, Ugur MC. A Simple HPLC-UV Method for Simultaneous Determination of Levetiracetam and Carbamazepine. Hacettepe Unv J Faculty Pharm. 2018;38(2):58-64.

19. Mahesh MVSK, Mahalaxmi M, et al. A Study of Method Development, Validation and Forced Degradation for Quantification of Carbamazepine and Oxcarbazepine by RP-HPLC. Int J Pharm Sci Rev Res. 2018:02:7-11.

20. Cristian T, Daniela B, Valentina A, et al. Development of a High Performance Chromatographic Method for Therapeutic Drug Monitoring of Carbamazepine based on an Experimental Design Approach. Farmacia. 2018;66(3):452-62.
21. Rashmin BP, Mrunali RP, Kashyap KB. Development and Validation of HPTLC Method for Estimation of Carbamazepine in Formulations and its in vitro Release Study. Chromat Res Int. 2011:461-70.

22. Fadhil MN, Muhammad SM. Four Spectrophotometric Methods for Simultaneous Determination of Carbamazepine and Lamotrigine in Binary Mixtures and Urine Samples. The Malaysian J Anal Sec. 2014;18(3):491-506.

23. Sadhana S, Ajit J, Santosh B. Development and Validation of UV-Visible Spectroscopic Method for Estimation of Carbamazepine in Bulk and Tablet Dosage Form. Int J Pharm Pharm Sec. 2006;8(2):514-22.

24. Eman YZ, Zayed MA. Spectrophotometric determination of carbamazepine and mosapride citrate in pure and pharmaceutical preparations. Arab J Chem. 2012;5(3):375-82.

25. Mohammed IW, Nahed EE, Hanany A. Validated spectrofluorimetric method for the determination of carbamazepine in pharmaceutical dosage forms after reaction with 4-chloro-7--nitrobenzo-2-oxa-1, 3-diazole (NBD-CI). Luminescence. 2015;30(7):1119-24.

26. Nityanand Z, Sadhana S, Ajit J. Development and Validation of UV-Visible Spectroscopic Method for Estimation of Carbamazepine in Bulk and Tablet Dosage Form. Int J Pharm Pharm Sci. 2015;8(2):234-8.

27. Hemanth A, Tippusulthan S, Chamundeswari K, et al. Development and validation of UV-visible spectroscopic method for estimation of Carbamazepine. Int J Innov Pharma Sci Res. 2017;5(2):42-51.

28. Maha MA, Nada SA. Analysis of Carbamazepine, Oxcarbazepine, Their Impurities and NonLabeled Interfering Substances by Stability-indicating UPLC/ MS/MS Method: Studying the Method's Greenness Profile. Chromatographia. 2018;81(11):1503-17.

29. Gwendolyn AM, Joetta MJ. Estimation of carbamazepine and carbamazepine-10, 11- epoxide concentrations in plasma using mathematical equations generated with two carbamazepine immunoassays. Am J Clin Pathol. 2010;133(5):728-36.

30. Jeffrey N, Pekka J, John TH, et al. Preparation and Physicochemical Characterization of aNovel Water-Soluble Prodrug of Carbamazepine. $J$ of Pharm Sec. 2010;99(4):1810-25.

31. Agnieszka D, Piotr MZ. New Insight into Thermodynamically Stability of Carbamazepine. J Pharm Sci. 2019;108(8):2654-60.

32. Hongxin $L$, Shanchong $C$, Xiao Z, et al. Structural elucidation, total synthesis, and cytotoxic activity of effphenol A. Organic and Biomolecular Chemistry 2018;48(1):8426-34.

33. Zhaoxia LI, Zhuanglei GAO. The Efficacy of Leviteracetam versus Carbamazepine for Epilepsy: A Meta-Analysis. Iran J Public Health. 2014;43(12):1616-26.

34. Aparecida LP, Beatriz A. The Efficacy of Leviteracetam versus Carbamazepine for Epilepsy. A Meta-Analysis. 2014;43(12):1616-26.

35. Gautam N, Mantha AK, Mittal S. Essential oils and their constituents as anticancer agents: A mechanistic view. Brazilian J Pharm Sci. 2014;50:878-84.

36. Zhen-li Q, Duan-feng Z. Thermal decomposition and non-isothermal decomposition kinetics of carbamazepine. Russian J Phy Chem A. 2014;88(13):2308-13.

37. Emma CE, James LM, Kevin BP, et al. Convenient syntheses of halo-dibenz[b,f] azepines and carbamazepine analogues via $\mathrm{N}$-arylindoles. Org Biomol Chem. 2013;11(48):8426-34.

Article History: Submission Date : 15-09-2020; Revised Date : 11-10-2020; Acceptance Date : 13-11-2020

Cite this article: Debnath S, Jeyaprakash MR, Sunidhi RC. Carbamazepine and its Synthesis Related Impurity Profile Compilation and Its Monograph Dispute for the Best Regulatory Practice- A Review. J Young Pharm. 2020;12(4):294-8. 